\title{
The Impact of Serious Safety Incidents on Airline Stocks
}

\author{
Jeffery A. Born ${ }^{1}$ \\ ${ }^{1}$ D'Amore-McKim School of Business, Northeastern University, Boston, Massachusetts, USA \\ Correspondence: Jeffery A. Born, Professor of Finance and Associate Dean of Undergraduate Education, \\ D’Amore-McKim School of Business, Northeastern University, Boston, Massachusetts, USA.
}

Received: January 16, 2021

Accepted: February 22, 2021

Online Published: March 18, 2021

doi:10.5430/ijfr.v12n4p1

URL: https://doi.org/10.5430/ijfr.v12n4p1

\begin{abstract}
The impact of commercial airplane crashes on the shareholder wealth of US-listed airline stocks has been the focus of many prior studies, but none have explored the concomitant impact on trading volume. We expand the scope of prior studies to include near crashes. We examine 262 'incidents' from 1962 to 2018 (220 with return evidence) and document a significant (negative) wealth impact for crashes with fatalities and casualties, and an insignificant impact for incidents with no casualties. We find that log-transformed trading volume spikes upward in the three-day crash-period window and that trading volume remains abnormally high in the three plus weeks that follow the crash when casualties occur. We interpret the high level of post-event trading to be consistent with a noise trader hypothesis: naïve trading hoping to take advantage of airline stock over-reaction - which we do not detect.
\end{abstract}

Keywords: airline crash, shareholder wealth, trading volume, 9/11

\section{Introduction}

The crash or near crash of a commercial airplane is almost always a devastating event for passengers and crew alike. Numerous studies document a significant negative impact of a crash on the market value of the airline. These studies generally conclude that relative the relative impact changed little with the de-regulation of the airline industry in the 1970s (although the riskiness of airline stocks rose) (Note 1), that competitors of the 'crash' airline experienced a small uptick in value consistent with an expected switching behavior by consumers, but there was also a small downtick in the value of all airlines consistent with the hypothesis that consumers were concerned about the overall safety of the industry (Note 2). There is evidence that the immediate response of the market is an over-reaction (based on the expected loss), but this inefficiency evaporates after a couple of trading days. (Note 3) Whilst the evidence is mixed, there seems to be a relationship between the size of the loss of life and the size of the market response. (Note 4)

With the benefit of hindsight, we note that the events of $9 / 11$ have ushered in an era of unprecedented air safety for US-based airlines. In our sample, we have 33 incidents in the post-9/11 era: an average of just 1.83 per year (Note 5). Of the 33 post-9/11 events, only 3 led to a complete loss of life on the flight ( $9 \%$ of the sub-sample), but 28 ( $84 \%$ of the sub-sample) ended with no fatalities. In contrast, the period from July 1962 to August 2001 had a total of 225 events (an average of 5.6 per year), of which 58 (25.6\%) led to a total loss of life on the flight. The pre-9/11 sub-period had 92 events (25.8\%) with fatalities and just 97 (47.7\%) with no loss of life. In short, the post-9/11 period has seen the rate of serious accidents fall by more than $2 / 3$ rds and the overwhelming majority of those events ended with no fatalities and no injuries. (Note 6)

This study updates our understanding of the impact of airline crashes, near-crashes, and accidents which took the life of ground personnel (but not passengers or crew) on shareholder wealth. This broader definition of an 'incident' provides an opportunity to more fully examine the behavior hypothesis put forward by Kaplanski and Levy (2010). We separate our sample into events before and after 9/11 (excluding those four crashes) but find the most insight comes when we separate our sample into accidents with fatalities (or casualties) and those without. In addition, we report evidence on how these incidents are associated with changes in trading volume. Whilst virtually all our evidence conforms to what one would expect in an informationally efficient market, we find the persistent increase in trading volume after accidents with casualties (with little promise of significant price changes) to be more consistent with the noise trader hypothesis. (Note 7) 


\section{Literature Review}

\subsection{Airline Accidents and Airline Incidents}

The Air Commerce Act of 1926 instructed the Secretary of Commerce to foster air commerce; designate and establish airways; establish, operate, and maintain aids to air navigation (but not airports); arrange for research and development to improve such aids; license pilots; issue airworthiness certificates for aircraft and major aircraft components; and investigate accidents. (Note 8) In June 1928 the Aeronautics Branch of the Department of Commerce set up a 5 member Accident Review Board with the intent of investigating the cause(s) of airplane crashes and thus, improves aviation safety. Amendments to the Air Commerce Act in 1934 gave the Accident Review Board the power to subpoena witnesses and strengthened the ability of the Secretary to make air safety policies At the dawn of commercial jet airline service, the Federal Aviation Act of 1958 created the Federal Aviation Agency (FAA) as the successor to the Civil Aeronautics Authority. In 1967 the FAA became the Federal Aviation Administration.

Any airplane-related accident leads to an examination by the FAA. There is frequently a second investigation of an airline incident by the National Transportation Safety Board (NTSB). NTSB investigations are not conducted with the intention of determining fault (but the final report can include a finding of fault). (Note 9) We include NTSB events in our sample when there is a loss of life, when there are injuries, or when the incident had a significant probability of casualties, but none occurred. (Note 10) This led to a preliminary data set of 263 incidents. Table One discloses the US airlines with ten or most incidents in the time period covered by this study.

Table 1. Airlines with ten or more incidents (1962-2018)

\begin{tabular}{ll}
\hline Airline & Number of Incidents \\
\hline American Airlines/AMR & 27 \\
\hline United Airlines/UAL/United Express & 24 \\
\hline Trans World Airlines & 22 \\
\hline Pan American Airlines & 18 \\
\hline Eastern Airlines/Eastern Express & 18 \\
\hline Continental Airlines & 14 \\
\hline USAir & 12 \\
\hline Southwest Airlines & 12 \\
\hline Others & 126 \\
\hline
\end{tabular}

Ho, Qiu and Tang (2013) examine the impact of crashes on shareholder wealth, segregating their sample into crashes that led to a loss of 100 lives (or more), those that led to fatalities between 10 and 99, and those with a loss of live less than 10. Like most previous studies, the authors do not include airline incidents that did not lead to a loss of life. The authors conclude that there is a positive relation between the number of fatalities and the extent of shareholder response. For completeness, we examine the shareholder wealth responses of incidents that resulted in 100 or more fatalities (including the loss of life on the ground). We report the identity of 18 events with a large loss of life (return data is available for 15 of these incidents) in Table Two.

Table 2. Airline incidents with more than 100 lives lost (1962-2018)

\begin{tabular}{llll}
\hline Airline & Date & Location & Loss of Life \\
\hline American Airlines & $11 / 12 / 2001$ & Belle Harbor, NY & $260+5$ on ground \\
\hline American Airlines (Note 11) & $9 / 11 / 2001$ & NYC \& Arlington, VA & $156+1725$ on ground \\
\hline United Airlines (Note 12) & $9 / 11 / 2001$ & NYC \& Shankville, PA & $109+900$ on ground \\
\hline Trans World Airlines* & $7 / 7 / 1996$ & East Moriches, NY & 230 \\
\hline
\end{tabular}




\begin{tabular}{llll}
\hline American Airlines & $12 / 12 / 1995$ & Buga, Columbia & 159 \\
\hline USAir & $9 / 8 / 1994$ & Aliquippa, PA & 132 \\
\hline United Airlines & $7 / 19 / 1989$ & Sioux City, IO & 112 \\
\hline Pan American Airlines & $12 / 21 / 1988$ & Lockerbie, Scotland & $259+11$ on ground \\
\hline Northwest Airlines & $8 / 16 / 1986$ & Romulus, MI & 154 \\
\hline Delta & $8 / 2 / 1985$ & Dallas, TX & $135+1$ on ground \\
\hline Pan American Airlines & $7 / 9 / 1982$ & New Orleans, LA & $145+8$ on ground \\
\hline American Airlines & $5 / 25 / 1979$ & Chicago, IL & $271+2$ on ground \\
\hline Pacific Southwest Airlines* & $9 / 25 / 1978$ & San Diego, CA & $135+7$ on ground + Cessna \\
\hline Pan American Airlines (Note 13) & $3 / 27 / 1977$ & Tenerife, Canary Islands & $335+248$ in KLM aircraft \\
\hline Eastern Airlines & $6 / 24 / 975$ & New York, NY & 113 \\
\hline Pan American Airlines & $4 / 22 / 1974$ & Bali, Indonesia & 107 \\
\hline Eastern Airlines & $12 / 29 / 1972$ & Miami, FL & 101 \\
\hline Alaskan Airlines* & $9 / 4 / 1971$ & Juneau, AL & 111 \\
\hline
\end{tabular}

*Machine readable returns unavailable

In Table Three we provide some descriptive statistics for the incidents that were included in this study. We start with Pan American Airways scheduled flight from San Juan, Puerto Rico to Montego Bay, Jamaica that encountered heavy turbulence and was forced to make an emergency landing in Kingston because of a severe injury to a member of the crew on November 9, 1962 (Note 14) and end with Delta Airlines scheduled flight from Atlanta to London, England on April 18, 2018 that reported a smoking engine at takeoff and was forced to immediately return for an emergency landing in Atlanta where firefighters immediately doused the damaged engine.

Table 3. Airline incident descriptive statistics (1962-2018)

\begin{tabular}{|c|c|c|c|c|c|}
\hline & \# & Average & Average & Average & Average \\
\hline & & Fatalities (Note 15) & Injuries (Note 16) & Casualties & On-Board \\
\hline Total Incidents & 262 & 23.78 & 14.91 & 38.69 & 98.75 \\
\hline Pre 9/11 excluding 9/11 & 225 & 24.94 & 16.03 & 40.97 & 92.42 \\
\hline Pre $9 / 11$ including $9 / 11$ & 229 & 25.67 & 16.03 (Note 17 ) & 41.70 & 91.95 \\
\hline Post 9/11 & 33 & 11.52 & 9.37 & 20.89 & 147.97 \\
\hline Incidents with fatalities & 137 & 45.49 & 26.42 & 71.91 & 85.23 \\
\hline Incidents without fatalities & 125 & - & 15.31 & 15.31 & 113.57 \\
\hline Incidents without casualties & 70 & - & - & 0.00 & 116.11 \\
\hline
\end{tabular}

It is worth noting that over time, the average seating capacity of commercial airlines and the proportion of seats filled on the average flight has risen substantially. Thus, the somewhat arbitrary decision by Ho, Qiu and Tang (2013) to label the group of crashes with 100 or more fatalities as 'large' excluded all incidents before 1971. The average number of flight fatalities amongst these 'large' incidents was 151.2 whilst the number of survivors and injuries were just a handful as more than half of these events had a $100 \%$ mortality rate (Note 18).

\subsection{The Legal and Economic Consequences of Airline Incidents}

The definition of what constitutes a 'common carrier' in the United States and, by extension, the potential liabilities that it faces has evolved over time. In general, a common carrier is any person or company that transports goods (Not e19) and/or people and it offers these services to the general public under a license or authority provided by a regulatory body. Railroads, bus lines, taxicab companies, phone companies, internet service providers, cruise ships 
(Note 20), motor carriers, canal operators, and public airlines are all considered common carriers in the US. A common carrier is absolutely liable for goods carried with it. (Note 21)

The liability that a US common carrier faces for the injury or death of a passenger (or third parties) is based either on international treaties/agreements, federal standards/regulations, or state common law/reasonable care standards. In the case of airline passengers, we can differentiate between passengers injured or killed on an international flight (Note 22) from those on a domestic flight. (Note 23) Most US courts hold an airline to the highest degree of care with respect to the safety of its passengers, although it is not considered to be an insurer of the passenger's safety. It is only responsible for acts of negligence. Thus, airline passengers have been held to assume the risks involved in the sudden occurrence of storms. (Note 24)

A public airline can be required to purchase insurance to cover a portion of the liability that it may be exposed to due to the injury or death of a passenger or the general public (to a $3^{\text {rd }}$ party, say from debris resulting from an accident). The airline can also obtain insurance coverage on the airplane itself when the it is in flight (Note 25), motion (e.g. taxiing) or at rest. Unless limited by applicable law, it is generally the case that negligence that leads to increasing (potential) liability as the injuries arising from the incident increase in severity (the extreme is death).

This leads us to expect a weak rank ordering of capital market responses to serious airline involvement. Whilst we do not replicate Ho Qui and Tang (1983), we expect market responses to airline incidents that involve the death of more than 100 deaths to be larger than those where the loss of life is smaller. Incidents that led to casualties (but no deaths), would be expected to suffer even smaller market reactions and finally, those that suffer no casualties at all should have the smallest market reactions.

\section{Methodology}

\subsection{Market Responses to Serious Airline Incidents}

We employ two measures of shareholder responses to serious incidents: market-adjusted returns and market-model estimated abnormal returns. Market-adjusted returns $\left(M A R_{t}\right)$ are defined as: $R_{j t}-R_{m t}$ where $R_{j t}$ is the firm's holding period return at time $t$ and $\mathrm{R}_{\mathrm{mt}}$ is the return on the market portfolio as proxied for by the equally-weighted average return on the CRSP index at time $t$. This measure implicitly presumes that the riskiness of the firm is equal to the risk of the market (i.e. a Beta of one) (Note 26). The MAR measure is biased upward (downward) if the true systematic risk of the firm is greater (less) than the market portfolio. Of the original sample of 263 events, we lost 3 observations because of two incidents for the same airline on the same day (Note 27) and another 40 events because of a complete return record.

A firm's abnormal return $\left(\mathrm{AR}_{\mathrm{j}}\right)$ is defined as: $\mathrm{R}_{\mathrm{jt}}-\mathrm{E}\left(\mathrm{R}_{\mathrm{jt}}\right)$, where $\mathrm{R}_{\mathrm{jt}}$ is the firm's holding period return at time $t$ and $\mathrm{E}\left(\mathrm{R}_{\mathrm{jt}}\right)$ is the expected return for the firm. We obtain an expected return by first estimating a slope $\left(\mathrm{B}_{\mathrm{j}}\right)$ and intercept $\left(\alpha_{\mathrm{jt}}\right)$ term from a single factor return model (i.e. 'market model') with as many as 225 trading days (but as few as 40) ending 26 trading days before the airline incident. We then define $E\left(R_{j t}\right)$ as: $\alpha_{j}+\left(B_{j} * R_{m t}\right)$, where $R_{m t}$ is the return on the equally-weighted CRSP index at time $t$. We estimate market-adjusted and abnormal returns for each of the 41 trading days centered on the date of the airline incident. We cumulate market-adjusted and abnormal returns in three windows in event time: 20 days to 1 day before the incident, the day of the incident $(t=0)$ to 2 days after the incident, and from event day 3 to +20 .

We report the market impact of airline incidents in Table 4. In order to conserve space, we omit reporting daily market-adjusted and abnormal returns for the entire event window $(-20$ to +20$)$. We report only the cumulative totals (CMAR and CAR, respectively) in the three event windows: the pre-crash window ( -20 to -1$)$, the event period ( $t=0$ to +2$)$, and the post-crash window $(+3$ to +20$)$. We also report the t-statistic which tests the hypothesis that the impact was equal to zero, and probability level associated with each of the t-statistics. Other test statistics and a fully listing by event day are available upon request. Because the Betas for the airline stocks in this study are so dramatically larger than one, we limit the discussion of the market model estimates of abnormal returns.

Table 4. Airline incidents and market impacts (1962-2018)

\begin{tabular}{lllllll}
\hline \multicolumn{2}{l}{ Panel A: All Events $(\mathbf{n = 2 2 0})$} & & & & \\
\hline Event Time & CMAR & t-statistic & P-level & CAR & t-statistic & P-level \\
\hline-20 to -1 & $-0.97 \%$ & -1.182 & .1187 & $-0.26 \%$ & -0.326 & .3723 \\
\hline 0 to 2 & -0.48 & -1.829 & .0327 & -0.58 & -1.893 & .0292 \\
\hline
\end{tabular}




\begin{tabular}{|c|c|c|c|c|c|c|}
\hline 3 to 20 & -0.80 & -1.025 & .1527 & $\begin{array}{l}-0.61 \\
\end{array}$ & -0.819 & .2064 \\
\hline \multicolumn{7}{|c|}{ Average Beta $=1.63 ;$ Median Bea $=1.54$} \\
\hline \multicolumn{7}{|c|}{ Panel B: Post 9/11/2001 $(n=23)$} \\
\hline Event Time & CMAR & t-statistic & P-level & CAR & t-statistic & P-level \\
\hline-20 to -1 & $-1.15 \%$ & -0.350 & .3632 & $-5.04 \%$ & -1.586 & .0563 \\
\hline 0 to 2 & 2.01 & 1.579 & .0572 & 2.00 & 1.624 & .0522 \\
\hline 3 to 20 & -2.12 & -0.678 & .2488 & -3.64 & -1.210 & .1131 \\
\hline \multicolumn{7}{|c|}{ Average Beta $=1.45 ;$ Median Beta $=1.37$} \\
\hline \multicolumn{7}{|c|}{ Panel C: Pre 9/11 (n=197) } \\
\hline Event Time & CMAR & t-statistic & P-level & CAR & t-statistic & P-level \\
\hline-20 to -1 & $-1.05 \%$ & -0.557 & .2889 & $0.22 \%$ & 0.258 & .3980 \\
\hline 0 to 2 & -0.75 & -1.995 & .0230 & -0.76 & -2.360 & .0091 \\
\hline 3 to 20 & -0.60 & -0.468 & .3199 & -0.28 & -0.070 & .4719 \\
\hline \multicolumn{7}{|c|}{ Average Beta $=1.66 ;$ Median Beta $=1.56$} \\
\hline \multicolumn{7}{|c|}{ Panel D: Incidents with Fatalities $(n=121)$} \\
\hline Event Time & CMAR & t-statistic & P-level & CAR & t-statistic & P-level \\
\hline-20 to -1 & $-1.76 \%$ & -1.625 & .0521 & $-0.91 \%$ & -0.859 & .1952 \\
\hline 0 to 2 & -1.45 & -3.461 & .0003 & -1.36 & -3.326 & .0004 \\
\hline 3 to 20 & -1.99 & -1.930 & .0268 & -1.29 & -1.280 & .1003 \\
\hline \multicolumn{7}{|c|}{ Average Beta $=1.62 ;$ Median Beta $=1.45$} \\
\hline \multicolumn{7}{|c|}{ Panel E: Incidents with Fatalities $>99(n=15)$} \\
\hline Event Time & CMAR & t-statistic & P-level & CAR & t-statistic & P-level \\
\hline-20 to -1 & $-1.71 \%$ & -0.525 & .2997 & $-0.71 \%$ & -0.266 & .4100 \\
\hline 0 to 2 & -6.71 & -5.312 & $.0001<$ & -6.97 & -5.687 & $.0001<$ \\
\hline 3 to 20 & -1.38 & -0.455 & .3281 & 0.07 & 0.025 & .4901 \\
\hline \multicolumn{7}{|c|}{ Average Beta $=1.48 ;$ Median Beta $=1.42$} \\
\hline \multicolumn{7}{|c|}{ Panel F: Incidents with Casualties $(n=174)$} \\
\hline Event Time & CMAR & t-statistic & P-level & CAR & t-statistic & P-level \\
\hline-20 to -1 & $-0.81 \%$ & -0.344 & .3656 & $-0.26 \%$ & -0.265 & .3954 \\
\hline 0 to 2 & -1.10 & -3.849 & $.0001<$ & -1.09 & -3.033 & .0012 \\
\hline 3 to 20 & -0.95 & 0.558 & .2885 & -0.55 & -0.627 & .2652 \\
\hline \multicolumn{7}{|c|}{ Average Beta $=1.60 ;$ Median Beta $=1.40$} \\
\hline \multicolumn{7}{|c|}{ Panel G: Incidents with Injuries $(n=53)$} \\
\hline Event Time & CMAR & t-statistic & P-level & CAR & t-statistic & P-level \\
\hline-20 to -1 & $-1.27 \%$ & -0.790 & .2166 & $-1.09 \%$ & -0.638 & .2631 \\
\hline 0 to 2 & -0.60 & -1.408 & .0825 & -0.44 & -1.165 & .1247 \\
\hline 3 to 20 & -0.22 & -0.125 & .4505 & -0.38 & -0.448 & .3280 \\
\hline \multicolumn{7}{|c|}{ Average Beta $=1.62 ;$ Median Beta $=1.58$} \\
\hline \multicolumn{7}{|c|}{ Panel H: Incidents with Zero Casualties (n=52) } \\
\hline Event Time & CMAR & t-statistic & P-level & CAR & t-statistic & P-level \\
\hline-20 to -1 & $-2.62 \%$ & -1.604 & .0543 & $-1.49 \%$ & -0.927 & .1768 \\
\hline 0 to 2 & -0.10 & -0.161 & .4361 & -0.28 & -0.455 & .3248 \\
\hline 3 to 20 & -0.15 & -0.095 & .4622 & -0.83 & -0.543 & .2932 \\
\hline
\end{tabular}


CMAR is the average cumulative market-adjusted return where the return on CRSP equally weighted index serves as the market portfolio proxy, $\mathrm{P}$-level is the probability level associated with the reported $\mathrm{t}$-statistic, CAR is the average cumulative abnormal return estimated with a single factor model $\left(\alpha_{j}+B_{j} R_{m}+\varepsilon_{j}\right)$ where the return on the CRSP equally weighted index services as the market portfolio proxy, and Beta $\left(B_{j}\right)$ is the market model slope coefficient for firm j.

In Panel A we report results obtained for the entire sample of incidents with complete return records $(n=220)$. This combines incidents which led to extraordinary losses of life with serious incidents that, none the less, had no casualties. We find that the pre- and post-incident periods had market impacts that were negative but not significantly different from zero. We find the three-day incident period CAR is negative and significantly different from zero at approximately the $3 \%$ significance level.

We then split the sample into incidents occurring post-9/11 and those pre-9/11 (including the 2 events from $9 / 11$ in the pre-9/11 subsample). We report results for the post-9/11 time period in Panel B. A first glance they seem counter-intuitive, the average announcement effect is positive and (almost) significantly different from zero at the $5 \%$ level. However, when we recall that the vast majority of post-9/11 events consist of a series of 'close-calls' but virtually no serious loss of life or casualties - the results make sense. On balance, investors are 'relieved' when they learn of the (relative) good fortune and there is uptick in returns. However, all the gain (and more) is lost in the post-event period.

The pre-9/11 results in Panel C look a lot like those for the entire sample - which isn't surprising as about $90 \%$ of the incidents were before date although the span of time covers about $70 \%$ of the entire period of analysis. This is consistent with the dramatic fall-off in serious airplane incidents since 9/11. The exclusion of the post-9/11 events improved the statistical significance of the three-day incidence period. The pre- and post-9/11 results hint of a more compelling way to segregate the date: by incidence-related casualties.

In Panel D we examine market responses to 121 airline incidences in our period of study that led to at least one fatality. The average three-day incidence period CAR is $-1.36 \%$ with a very high significance level. The pre- and post-incidence periods also have negative CARs, and the post-announcement period is (nearly) significantly different from zero at the $10 \%$ level. The continuing post-incident downward drift in the airline stock requires some additional analysis.

In Panel $\mathrm{E}$ we report the market responses to 15 airplane crashes that results 100 fatalities or more. The average three-day incidence period CAR is $-6.97 \%$ - about $4.5 \mathrm{X}$ the result reported in Panel D. This magnitude of this impact is consistent with the result reported by Ho, Qiu and Tang (2013). We note that average CAR in the post-announcement period is not statistically significant and it has a positive sign. This suggests that the post-announcement period results reported in Panel D are driven by incidences with less than 100 fatalities.

In Panels F, G and H, we segregate our sample into incidents based on the type of injuries. Panel F reports results for 174 incidents with casualties (fatalities and/or injuries). Panel $\mathrm{G}$ reports results for the 53 incidents that had just injuries (no fatalities). Lastly, Panel $\mathrm{H}$ reports results for the 52 serious incidents that had no casualties. As we move through the panels, the nature of the physical damage to passengers and crew diminishes, but the legal liability might not. (Note 28)

The average three-day incidence period CAR in Panel $\mathrm{F}$ is $-1.09 \%, 27$ basis points smaller than result obtained when the analysis is restricted to accidents with fatalities (even as few as one). The post-incidence period's (insignificant) average CAR is 74 basis points smaller than the result obtained from the 'all fatalities' sub-sample. The average three-day incidence period CAR in Panel G (injuries only) is $-0.44 \%$, and it is not significantly different from zero.

Lastly, we come to 52 serious incidents (Panel $\mathrm{H}$ ) where there were no casualties of any kind reported. None of the average CARS prove to be statistically significant. This result was expected, but it does not support the Kaplanski and Levy (2006) behavioral hypothesis. (Note 29) Our findings suggest that the market tends to shrug off airline incidents that don't involve casualties. A behavior model prediction might suggest a positive response for the airline that 'dodged the bullet' and avoided any harm to its passengers and crew. (Note 30)

\subsection{Trading Volume Responses to Airline Incidents}

Daily trading volume is inherently more volatile than daily holding period returns, and its 'raw' distribution is decidedly not normal. However, the distribution of the natural log of trading volume produces data that is distributed (approximately) normal. (Note 31) Whilst there is no theoretical model of trading volume, we take advantage of WRDS procedures to develop an abnormal trading volume metric that is roughly equivalent to market-model abnormal returns. 
A firm's abnormal volume $\left(A V_{j}\right)$ is defined as: $n \log V_{j t}-n \log E\left(V_{j t}\right)$, where $V_{j t}$ is the firm's trading volume at time $t$ and $\mathrm{E}\left(\mathrm{V}_{\mathrm{jt}}\right)$ is the expected trading volume. We obtain an expected trading metric by first estimating a slope $\left(\mathrm{B}_{\mathrm{j}}\right)$ and intercept $\left(\alpha_{\mathrm{jt}}\right)$ term from a single factor return model (i.e. 'market model') with as many as 225 trading days (but as few as 40) ending 26 trading days before the airline incident. We then define $n \log E\left(V_{j t}\right)$ as: $\alpha_{j}+\left(B_{j} * n \log \left[V_{m t}\right]\right)$, where $\mathrm{V}_{\mathrm{mt}}$ is the volume for the New York and American Stock Exchanges at time $t$. We estimate abnormal volumes for each of the 41 trading days centered on the date of the airline incident. We cumulate abnormal volumes (CAV) in three windows in event time: 20 days to 1 day before the incident, the day of the incident $(t=0)$ to 2 days after the incident, and from event day 3 to +20 .

We report trading volume results in Table Five. We cumulate daily abnormal volumes for the 20-day pre-incident period, the three-day incident period, and the 18-day post-incident period, plus the mean (daily) abnormal return volume in each sub-period. We also report the daily abnormal returns for each of the three days in the event window $(\mathrm{t}=0,1$, and 2$)$. Lastly, we report $\mathrm{t}$-statistics and their associated probability levels.

Table 5. Airline incidents and trading volume impacts (1962-2018)

\begin{tabular}{llllllll}
\hline \multicolumn{2}{l}{ Panel A: All Events $(\mathbf{n}=\mathbf{2 1 5})$} & & & & & \\
\hline Event Time & CAV & Mean AV & t-stat & P-level & Day & AV & P-level \\
\hline-20 to -1 & $-8.71 \%$ & $-0.44 \%$ & -0.447 & .3275 & 0 & $5.38 \%$ & .0015 \\
\hline 0 to 2 & 26.42 & 8.81 & 3.500 & .0002 & 1 & 19.85 & $.0001<$ \\
\hline 3 to 20 & 23.38 & 1.30 & 1.264 & .1031 & 2 & 1.19 & .6912 \\
\hline
\end{tabular}

Panel B: Post 9/11 (n=23)

\begin{tabular}{llllllll}
\hline Event Time & CAV & Mean AV & t-stat & P-level & Day & AV & P-level \\
\hline-20 to -1 & $-180.12 \%$ & $-9.01 \%$ & -5.532 & $.0001<$ & 0 & $-0.65 \%$ & .3063 \\
\hline 0 to 2 & 20.63 & 6.88 & 1.636 & .0509 & 1 & 13.23 & 0.824 \\
\hline 3 to 20 & -133.77 & -7.43 & 4.330 & $.0001<$ & 2 & 8.05 & .2093 \\
\hline
\end{tabular}

Panel C: Pre 9/11 (n=192)

\begin{tabular}{llllllll}
\hline Event Time & CAV & Mean AV & t-stat & P-level & Day & AV & P-level \\
\hline-20 to -1 & $21.59 \%$ & $1.08 \%$ & 1.000 & .1586 & 0 & $4.00 \%$ & .2482 \\
\hline 0 to 2 & 22.89 & 7.63 & 2.738 & .0031 & 1 & 19.93 & .0002 \\
\hline 3 to 20 & 37.57 & 2.09 & 1.835 & .0333 & 2 & -1.04 & .2828
\end{tabular}

Panel D: Incidents with Fatalities (n=117)

\begin{tabular}{llllllll}
\hline Event Time & CAV & Mean AV & t-stat & P-level & Day & AV & P-level \\
\hline-20 to -1 & $-85.19 \%$ & $-4.26 \%$ & -2.984 & .0014 & 0 & $4.23 \%$ & .2012 \\
\hline 0 to 2 & 22.39 & 7.46 & 2.025 & .0215 & 1 & 23.05 & .0002 \\
\hline 3 to 20 & 112.90 & 6.27 & 4.168 & $.0001<$ & 2 & -4.89 & .3487 \\
\hline
\end{tabular}

Panel E: Incidents with Fatalities > $99(n=15)$

\begin{tabular}{llllllll}
\hline Event Time & CAV & Mean AV & t-stat & P-level & Day & AV & P-level \\
\hline-20 to -1 & $-121.22 \%$ & $-6.02 \%$ & -4.348 & .0003 & 0 & $3.62 \%$ & .2892 \\
\hline 0 to 2 & 36.34 & 12.11 & 6.885 & $.0001<$ & 1 & 28.43 & $.0001<$ \\
\hline 3 to 20 & 143.78 & 8.45 & 5.124 & $.0001<$ & 2 & 6.17 & .1067 \\
\hline
\end{tabular}

Panel F: Incidents with Casualties (n=169)

\begin{tabular}{llllllll}
\hline Event Time & CAV & Mean AV & t-stat & P-level & Day & AV & P-level \\
\hline-20 to -1 & $8.14 \%$ & $0.41 \%$ & 0.346 & .3648 & 0 & $8.69 \%$ & .0297 \\
\hline 0 to 2 & 28.61 & 9.54 & 3.137 & .0009 & 1 & 22.08 & $.0001<$ \\
\hline
\end{tabular}




\begin{tabular}{|c|c|c|c|c|c|c|c|}
\hline 3 to 20 & 103.95 & 5.78 & 4.653 & $.0001<$ & 2 & -2.16 & .2154 \\
\hline \multicolumn{8}{|c|}{ Panel G: Incidents with Injuries(n=53) } \\
\hline Event Time & CAV & Mean AV & t-stat & P-level & Day & $\mathrm{AV}$ & P-level \\
\hline-20 to -1 & $25.19 \%$ & $1.26 \%$ & 1.274 & .1042 & 0 & $1.23 \%$ & .2688 \\
\hline 0 to 2 & 3.24 & 1.08 & 0.964 & .1698 & 1 & 0.86 & .4244 \\
\hline 3 to 20 & 138.55 & 8.15 & 3.884 & $.0001<$ & 2 & 1.15 & .3876 \\
\hline \multicolumn{8}{|c|}{ Panel H: Incidents with Zero Casualties $(n=52)$} \\
\hline Event Time & CAV & Mean AV & t-stat & P-level & Day & AV & P-level \\
\hline-20 to -1 & $9.73 \%$ & $0.49 \%$ & 0.256 & .3988 & 0 & $9.91 \%$ & .1644 \\
\hline 0 to 2 & 59.32 & 19.77 & 4.036 & $.0001<$ & 1 & 30.33 & .0020 \\
\hline 3 to 20 & -37.25 & -2.07 & 1.035 & .1504 & 2 & 19.07 & .0332 \\
\hline
\end{tabular}

Panel A reports results obtain with all incidents. We find trading volume spikes up significantly in the three-day event window and that this increase in trading volume is observed on the day of the event $(t=0)$ and the day after $(\mathrm{t}=1)$. This pattern in trading volume is consistent with return evidence reported in Panel A of Table Four. The sharp rise in trading volume around the time of an (airline) incident is consistent with the hypothesis that the event brings the firm to the attention of a large audience - some of whom trade in the shares in hope of earning a profit. (Note 32)

Panel B reports results for all incidents that occurred after 9/11/01. We are not sure how to interpret the significantly lower trading volume in the pre-event period, but we note that this sub-period is associated with negative and significant CAR. Trading volume rises sharply (5.09\% significance level) in the three-day event window and abnormally high trading volume persists in the 18-day post-incident sub-period.

Panel $\mathrm{C}$ reports results for incidents that occurred prior to $9 / 11$. There was a sharp rise in trading volume during the three-day incident period, with the day after the incident showing the most pronounced increase in volume. Abnormally high trading volume continued during the 18-day post-incident period, although there was no systematic 'reward' (i.e. abnormal CAR) to these traders.

Panel D reports results for incidents that led to a loss of life. As with the pre-9/11 sub-sample, there is abnormally low trading volume in the pre-incident period. The three-day incident window exhibits a significant increase in trading volume, the day after the incident having the only statistically significant increase in volume. Trading remains abnormally high in the 18-day post-incidence sub-period, and there is a modest statistically significant 'reward' to short-sellers (i.e. a negative CAR that is significant at the $10.03 \%$ level).

Panel E reports results for incidents that led to tremendous loss of life. The abnormal trading volume evidence shows an identical pattern with results reported in Panel D: a large spike upward in the incident and post-incident period. However, as reported in Table Four, these tragic incidents were fully priced out in the three-day incident period there was no significant post-incident drift in abnormal returns (the CAR was actually positive). Thus, post- incident noise traders who sold the airline's stock short in the hope of cashing in on a further decline in share prices did not reap profits from that strategy (and may have actually suffered losses).

Panel F reports results for all incidents with casualties. The trading volume pattern is consistent with Panels D and E: an upward tick in abnormal trading volume in the three-day incident period and the 18-day post-incident period. We do report statistically significant abnormal trading volume on event date 0 (day of the incident) and the day after $(\mathrm{t}=1)$.

Panel G reports results for all incidents where there were injuries - but no fatalities. We detect no abnormal trading volume except in the 18-day post-incident sub-period. As there are no abnormal returns associated with any of the sub-periods, we conclude that the post-announcement upward spike in trading volume can be characterized as noise trading (with no systematic payoff).

Lastly, in Panel $\mathrm{H}$ we report results for incidents that normally would have been expected to produce some injuries and/or fatalities but for which there were zero casualties. There was an abnormally large increase in trading volume in the three-day event sub-period, corresponding to event days 1 and 2 (the two post-incident days). Unlike the other sub-samples examined - the post-incidence period was not characterized by continuing high levels of trading. The 
incident drew some initial trading interest in the airline's stock, but this seems to evaporate soon after investors determined that there were no injuries or deaths.

\section{Summary and Conclusion}

We add several new features to the literature that examines investor responses to airline crashes. First, we include incidents that did not lead to any loss of life and, for the first time, we include incidents that would normally have been severe enough to be associated with a loss of life and/or injuries. We find what one would expect - as the human carnage associated with an incidence diminishes, so too the price impact of the incident diminishes.

Our study extends 17 years past the tragic events of $9 / 11$. The tremendous increase in airport screening since $9 / 11$ is but one of the changes that we observe in air travel - the post-9/11 period has seen a $2 / 3$ rds reduction in the annual frequency of airline crashes/serious incidences and virtually an end to airline incidents that are associated with a loss of life. Not surprisingly, the response of investors to post-9/11 airline incidents has been smaller that those observed before that tragic day.

The other new feature we bring to this literature is an examination of trading volume in the 41-day event window centered on the incident. Except for one sub-sample (incidents with injuries but no fatalities), we find positive abnormal trading volume in the three-day event (days 0, 1, and 2). Moreover, we find the 18-day post-incident period is characterized by abnormally high trading volume for all sub-samples except incidents that had no casualties. This post-incident trading is never associated with statistically significant (at the $10 \%$ level or below) abnormal returns.

We conclude from our analysis of trading volume that an airline incident does increase investor awareness of the airline and trading volume. We believe that the persistence in abnormally high trading volume in the post-incident period is consistent with noise traders hoping to take advantage of an incomplete market response to news of the incident or hoping to profit from an over-reaction to initial event. We find no evidence in support of either trading strategy yielding systematic profits. We conclude that over the forty plus years of airline operations (and crashes) prior to our study, sophisticated investors had come to learn how to efficiently price out airline incidents and that noise traders hoping to capture market inefficiencies almost always saw their hopes dashed. The only consistent winners who trade airline stocks based on safety incidents that we can detect, were their brokers.

\section{Acknowledgements}

The author wishes to thank the referee and the editor for their valuable comments and suggestions. The author also wishes to thank Anya Mkrtchyan, John Bai, and Kuncheng Zheng for their helpful comments on earlier drafts. All errors are the responsibility of the author.

\section{References}

Ajinkya, B. B., \& Jain, P. C. (1989). The behavior of daily stock market trading volume. Journal of Accounting and Economics, 11(4), 331-359. https://doi.org/10.1016/0165-4101(89)90018-9

Barrett, W. B., Heuson, A. J., Kolb, R. W., \& Schropp, G. H. (1987). The adjustment of stock prices to completely unanticipated events. Financial Review, 22(4), 345-354. https://doi.org/10.1111/j.1540-6288.1987.tb01258.x

Bosch, J. C., Eckard, E. W., \& Singal, V. (1998). The competitive impact of air crashes: Stock market evidence. The Journal of Law and Economics, 41(2), 503-519. https://doi.org/10.1086/467399

Briddon, A. E., Champie, E. A., \& Marraine, P. A. (1974). FAA historical fact book: A chronology, 1926-1971. Federal Aviation Administration, Office of Information Services.

Bruning, E. R., \& Kuzma, A. T. (1989). Airline accidents and stock return performance. The Logistics and Transportation Review, 25(2), 157-169.

Cavarra, L. A., Stover, R. D., \& Allen, B. J. (1981). The capital market effects of airline deregulation. Transportation Journal, 73-78.

Chance, D. M., \& Ferris, S. P. (1987). The effect of aviation disasters on the air transport industry: a financial market perspective. Journal of Transport Economics and Policy, 151-165.

De Long, J. B., Shleifer, A., Summers, L. H., \& Waldmann, R. J. (1987). The economic consequences of noise traders (No. w2395). National Bureau of Economic Research. https://doi.org/10.3386/w2395

Fama, E. F. (1991). Efficient capital markets: II. Journal of Finance, 46(5), 1575-1617. https://doi.org/10.1111/j.1540-6261.1991.tb04636.x

Ho, J. C., Qiu, M., \& Tang, X. (2013). Do airlines always suffer from crashes?. Economics Letters, 118(1), 113-117. 
https://doi.org/10.1016/j.econlet.2012.09.031

Kaplanski, G., \& Levy, H. (2010). Exploitable predictable irrationality: The FIFA World Cup effect on the U.S. stock market. Journal of Financial and Quantitative Analysis, 45(2), 535-553. https://doi.org/10.1017/S0022109010000153

Liu, Y., Peng, G., Hu, L., Dong, J., \& Zhang, Q. (2019). Using Google Trends and Baidu Index to analyze the impacts of disaster events on company stock prices. Industrial Management \& Data Systems. https://doi.org/10.1108/IMDS-03-2019-0190

Pagan, R. (1981). English carrier's comm-law right to reject undeclared Cargo. The Myth of the Closed-Container Conundrum. William \& Mary Law Review, 23, 791-833.

Wilson, L., \& Anderson, W. (1942). Liability of Air Carriers. Journal of Air Law and Commerce, 13, 281-303.

\section{Notes}

Note 1. See Cavarra, Stover and Allen (1981), Barrett, Heuson, Kolb, and Schropp (1987), or Bruning and Kuzma (1989).

Note 2. See Bosch, Eckard and Singal (1998).

Note 3. See Kaplanski and Levy (2010).

Note 4. See Chance and Ferris (1987) and Ho, Qiu, and Tang (2013).

Note 5. On February 12, 2009 Colgan Air Flight 3407 from Newark to Buffalo crashed just prior to arrival killing all 49 passengers and crew on board and one person on the ground. As of this writing, this was the last flight to suffer a loss of life in the US. There was an accident involving a Southwest Airlines flight that led to the death of an employee on the ground on April 17, 2018. For firms in our sample, that last incident that resulted in a loss of life was the Comair (a Delta connector) Flight 5191 that crashed on take-off from Lexington, KY on August 27, 2006.

Note 6. It is no exaggeration to say that since $9 / 11$ the most dangerous part of air travel has been getting to and from the airport.

Note 7. See DeLong et. al. (1987) for a discussion of noise traders and their economic consequences for capital markets and society.

Note 8. See Briddon, Champie and Marraine (1974) for a discussion of the history of air commerce regulation and agencies.

Note 9. Because all NTSB accident reports since 1962 are available in a searchable data base on-line, we opted to focus on these reports. Whilst the FAA data base is more extensive, there are no serious incidents involving scheduled air service that have not been investigated by the NTSB.

Note 10. The most frequently excluded NTSB event is when an encounter with severe air turbulence leads to an unscheduled (and uneventful) landing and collisions between taxiing aircraft on the ground where no casualties occur. Examples of events where no casualties occurred but the incident was included are: landing gear failures, engine failures, or near misses with other aircraft whilst in the air. Hijackings of airplanes were also excluded unless the event led to a casualty for someone other than the hijacker(s).

Note 11. The sum of losses from two separate hi-jacked flights.

Note 12. The sum of losses from two separate hi-jacked flights.

Note 13. Most consider this to be the worst commercial airline accident (not involving a hi-jacking) to date.

Note 14. Approximately four months after the beginning of daily return availability from CRSP.

Note 15. Fatalities amongst passengers and crew only.

Note 16. Early NTSB reports clump minor injuries together with no injuries and separate out 'serious' injuries. As a result, injury statistics and incidence rates are likely biased downward (particularly for incidents that occurred pre 9/11).

Note 17. Reliable data on the number of injuries caused by events of $9 / 11$ are not available.

Note 18 . The average mortality rate for passengers and crew aboard these 'large' incidents was $89.26 \%$.

Note 19. Including voice and data communications thanks to the Communications Act of 1934. 
Note 20. But excluding ocean freight forwarders in the United States.

Note 21. Case law stemming from the Lovett v Hobbs (1680) [England] as described in Pagan (1981).

Note 22. The Warsaw Convention (1929) limited liability to $\$ 8,300$ for each international airline flight injury or fatality, unless the plaintiff could prove airline or crew misconduct. This was superseded by the Montreal Convention (1999) which raised the limit to 113,100 SDR (special drawing rights).

Note 23. Including passenger casualties on a flight that originated and was intended to be completed entirely in the United States, even when the airline is domiciled outside the United States.

Note 24. This includes injury or death that can be argued to be foreseeable - not just negligence. See Wilson and Anderson (1942) for a discussion.

Note 25. Which includes take-offs and landings.

Note 26. The average and median estimated slope coefficients were 1.63 and 1.54 , respectively.

Note 27. American Airlines 9/11/01, United Airlines 9/11/01, and USAir 6/9/05, a near-miss at Boston Logan airport).

Note 28. It is often the case that an individual who sustains significant injuries can receive a larger settlement than the estate of who has wrongfully lost their life.

Note 29. The authors argued that the size of the decline in shareholder wealth immediately following an airline crash with fatalities (about $\$ 6$ billion) could not be explained by the actual size of losses (about $\$ 1$ billion). This, plus the fact that the total value of the shareholder loss was reversed in just a couple of days after the event the authors argue is evidence of an irrational initial response to the crash, but is consistent with a behavioral research finding that individuals exhibit a 'larger' response to bad news than good news.

Note 30. A majority of these 'no casualty' incidents did lead to damage to the aircraft. Neither the NTSB or the FAA report on the amount of damages - although they do note if the plane was considered a 'total loss.' The extent to which the airline was ultimately indemnified for some or all of the loss is also not noted.

Note 31. See Ajinkya and Jain (1989).

Note 32. See Liu et. al (2019) for evidence that Google searches rise sharply immediately following a disaster.

\section{Copyrights}

Copyright for this article is retained by the author(s), with first publication rights granted to the journal.

This is an open-access article distributed under the terms and conditions of the Creative Commons Attribution license (http://creativecommons.org/licenses/by/4.0/). 